\title{
Neck Disorders among Construction Workers: Understanding the Physical Loads on the Cervical Spine during Static Lifting Tasks
}

\author{
Ashish D. NIMBARTE ${ }^{1 *}$, Fereydoun AGHAZADEH ${ }^{2}$, \\ Laura H. IKUMA ${ }^{2}$ and Craig M. HARVEY ${ }^{2}$
${ }^{1}$ Industrial and Management Systems Engineering, West Virginia University, PO Box 6070, Morgantown, WV 26506-6107, USA
${ }^{2}$ Department of Construction Management and Industrial Engineering, Louisiana State University, Baton Rouge, LA 70803-6419, USA

Received May 14, 2009 and accepted July 29, 2009

\begin{abstract}
In this study a common yet very strenuous construction work activity, was evaluated biomechanically by studying electromyography (EMG) of the major neck muscles. The muscles studied were the sternocleidomastoid and the upper trapezius. Fifteen healthy participants (10 males and 5 females) with no history of musculoskeletal abnormalities participated in this study. The participants lifted $25 \%, 50 \%$, and $75 \%$ of their maximum shoulder height static strength at neutral, maximally flexed, and maximally extended neck postures. The weight lifted as well as the neck posture significantly affected the activities of the neck muscles. Increase in the weight increased the activation of the neck muscles. The sternocleidomastoid muscle was most active at the extended neck posture, while the upper trapezius muscle was most active at the flexed neck posture. The results of this study indicate that the neck muscles play an active role during lifting and holding tasks at shoulder height. Thus, such tasks could be probable risk factors associated with neck disorders prevalent among construction workers.
\end{abstract}

Key words: Neck muscle electromyography, Lifting, Musculoskeletal disorders, Construction workers

\section{Introduction}

Construction is one of the most hazardous industries in the United States ${ }^{1}$. Work-related musculoskeletal pain and disorders are common among construction trade workers and account for over $37 \%$ of all injuries resulting in days away from work ${ }^{2)}$. The incidence rate of work-related non-traumatic soft tissue injuries to the neck, back, and upper extremities is about 6.2 per 100 full time employees in the construction industry, which is highest of all the US industries ${ }^{3)}$. Furthermore, construction injuries from manual material handling are costly, accounting for $32 \%$ of workers' compensation claims among the construction trade workers, and $25 \%$ of the cost of all claims across all the industries. The average

*To whom correspondence should be addressed.

E-mail: nimbarte.ashish@gmail.com cost per claim is USD 9,2401).

Frequent material handling activities found in construction work environments put substantial stress on the neck, shoulder, and lower back resulting in pain and discomfort. A number of studies have evaluated the prevalence of different types of musculoskeletal disorders (MSD) among construction workers. A study of workers compensation claims in Washington (US) show that masonry and residential construction are among the top five industries having the highest risk of injuries ${ }^{4}$. Among 73,631 Swedish construction workers studied by Holmström et al. ${ }^{5}$, $41.1 \%$ had neck and shoulder disorders. Building construction is listed among the top ten high-risk industries for MSD among the Taiwanese working population by Guo et $a l^{6}$. Neck and shoulder disorders affect $26.3 \%$ of male and $32.1 \%$ of female among the Taiwanese construction workers.

Construction workers are frequently involved in the lift- 
ing of heavy objects at the ground, knee, waist, elbow, shoulder, and overhead heights. Due to material and site constraints, construction workers spend ample time lifting, holding, carrying, pulling or pushing loads of material. For instance, the mixing of mortar or grout traditionally involves lifting heavy cement bags. Full cement bags weigh around 36 to $45 \mathrm{~kg}$. Regular masonry work involves lifting of concrete blocks at or above shoulder level. Standard-weight concrete blocks, measuring $0.2 \times 0.2 \times 0.4 \mathrm{~m}$, weigh approximately $16 \mathrm{~kg}^{7}$. The installation of large windows and sheet materials requires workers to lift and carry heavy and bulky objects. Wall panels used in residential construction, which are manually handled by $1-2$ workers, can measure $3.66 \times 2.44 \mathrm{~m}$ and weigh up to $118 \mathrm{~kg}$ when sheathed ${ }^{8)}$. These and many more construction related activities involve lifting, holding, and carrying of heavy objects. In addition to the weight of objects, construction work activities at shoulder height are often considered cumbersome due to awkward posture of the neck.

Manual material handling activities are an inseparable part of any construction project. Epidemiologically, several review studies have clearly established a strong relationship between work activities requiring forceful arm exertions and the occurrence of neck disorders ${ }^{9-11)}$. Common neck disorders associated with work activities involving forceful arm exertions include degenerative disc disorders such as disc herniation or cervical spondylosis and in some cases more muscle specific disorders such as tension neck syndrome ${ }^{12,13)}$. Even though these disorders are prevalent among construction workers, very few studies have evaluated the underlying pathomechanism. The purpose of this study was to evaluate physical risk factors (force and posture) associated with neck disorders among construction workers. The role of the major neck muscles during lifting tasks at shoulder height was evaluated biomechanically by studying muscle activity in the cervical region.

\section{Subjects and Methods}

\section{Participants}

Fifteen healthy participants (10 males and 5 females) with no history of musculoskeletal abnormalities participated in this study. The participants were graduate or undergraduate students at Louisiana State University. Age, weight, height, and BMI of the participants were $23.9 \pm 3.8 \mathrm{yr}, 76.7 \pm 14.1 \mathrm{~kg}$, and $172.8 \pm 11.6 \mathrm{~cm}$, and $25.6 \pm 3.5$, respectively. The Physical Activity Readiness Questionnaire (PAR-Q, British Columbia Ministry of Health) was used to screen participants for cardiac and other health problems (e.g. dizziness, chest pain, heart trouble). Participants who answered yes to any of the

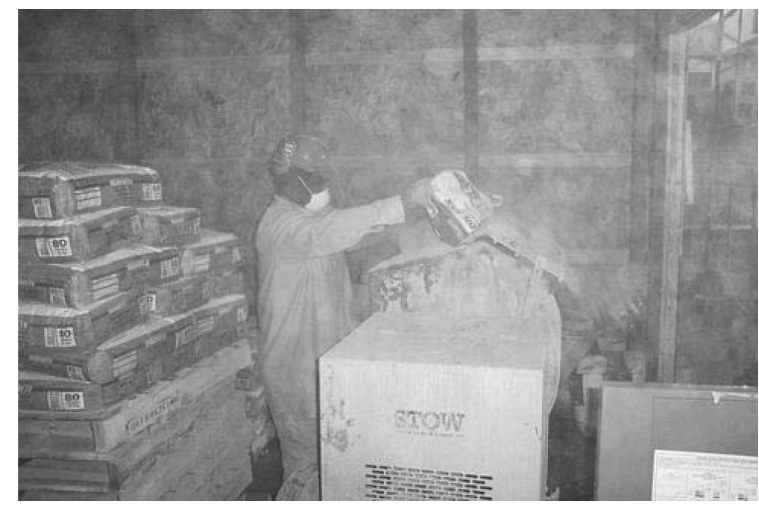

Fig. 1. A construction worker lifting and holding a heavy cement bag at shoulder height during mixing mortar (source: NIOSH Publication No. 2007-122).

questions on the PAR-Q were excluded. Prior to the data collection the experimental procedures and the demands of the testing were explained to the participants and their signature was obtained on the informed consent form approved by the institutional review board at Louisiana State University.

\section{Experimental task}

The experimental task was designed to test a common yet physically demanding construction work activity especially for the upper extremities. As described previously, construction workers are frequently involved in lifting and holding objects at shoulder height. One such task is mixing mortar in the traditional way. To load material in the mixer, construction workers have to lift and hold heavy cement bags to their shoulder height ${ }^{1)}$ (Fig. 1). Lifting at shoulder height is considered to be very strenuous for the shoulder joint due to a comparatively larger moment arm. Furthermore at various instances construction workers tend to perform forceful exertions at extended and flexed neck postures because of necessary visual focus points (e.g. carrying objects up- or down- stairs and on ladders, holding materials while standing on inclined surfaces). Therefore, the lifting tasks evaluated in this study were carried out at shoulder height in extended, neutral, and flexed neck postures. Studying static exertions at extreme postures provide a sound basis for understanding neck muscles' activation at different muscle lengths. In order to standardize the posture, the participants performed lifting trials at maximally extended and flexed neck postures. The neck flexion extension angles were measured using a manual goniometer by aligning one hand of the goniometer with the chin line and the other with the neck along the mastoid process. The average maximum neck flexion and extension angles were $54.6^{\circ}\left( \pm 10.1^{\circ}\right)$ and $46.3^{\circ}\left( \pm 9.0^{\circ}\right)$, respectively. 


\section{Experimental design}

At each neck posture, participants lifted $25 \%, 50 \%$, and $75 \%$ of their maximum shoulder height static strength. Thus, each participant performed nine experimental trials ( 3 neck postures $\times 3$ lifting weights). A full factorial experimental design was adopted and the trial order was randomized using Latin Square design. The independent variables were lifting weight $(25 \%, 50 \%$, and $75 \%)$ and neck posture (maximally extended, neutral, and maximally flexed). The dependent variables were the activities of the sternocleidomastoid and upper trapezius muscles measured using electromyography (EMG).

The maximum shoulder height static strength was determined using isometric strength testing equipment (Prototype Design \& Fabrication Company, Ann Arbor, MI, USA). The equipment consists of a horizontal lever arm (C) and a vertical post (D) (Fig. 2). A load cell (B) is mounted on a horizontal lever arm. The horizontal lever arm is assembled to a vertical post, such that it could be moved along the vertical post and clamped at any desired height. The height of the handle (A) was adjusted to the approximate shoulder height of the participants such that the participants maintained exactly the same joint configuration as during the experimental trials. Output from the load cell was recorded using a force monitor. The participants were instructed to apply the force slowly and steadily without jerking motion, until maximum exertion was reached. Three trials were collected. In case of variability of $>10 \%$ between trials, a fourth trial was performed and the average of the best three values was determined.

During each experimental trial, the participant stood in the normal upright standing posture with her/his feet placed symmetrically and shoulder width apart. The par- ticipant lifted a box with cutout handles on each side such that the shoulder joint was approximately $0^{\circ}$ abducted and $90^{\circ}$ flexed and elbow joint $15^{\circ}-20^{\circ}$ degrees flexed with neutral supination/pronation (Fig. 2). The wrist was approximately $35^{\circ}-45^{\circ}$ degrees ulnarly deviated to facilitate firm coupling with the box. The participants lifted and held the box for seven seconds. First two seconds were allowed for lifting the box and during the remaining five seconds they held the box. To standardize the posture across the participants, a movable platform was used (Fig. 3). Every time the height of the lifting box was adjusted approximately to the shoulder height of the participants by moving the platform up or down. Before the actual experimental trial, participants would stand at a convenient distance from the box making sure that he or she could lift the box by maintaining the required joint configuration. Goniometers were used to maintain consistent joint configurations across the participants. Each participant performed all nine exertions ( 3 weights $\times 3$ neck postures) in one session. A rest period of $1.5 \mathrm{~min}$ was given between the trials. To avoid excessive axial rotation of the upper arm, two different boxes, $30 \mathrm{~cm}$ wide $(30 \mathrm{~cm} \times 30 \mathrm{~cm} \times 20 \mathrm{~cm})$ and $42 \mathrm{~cm}$ wide $(25 \mathrm{~cm} \times$ $42 \mathrm{~cm} \times 20 \mathrm{~cm}$ ), were used. Participants with a shoulder width less than $35 \mathrm{~cm}$ simulated the lifting tasks using the $30 \mathrm{~cm}$ wide box, while the participants with a shoulder width more than $35 \mathrm{~cm}$ used the $42 \mathrm{~cm}$ wide box. The weight of the box was adjusted to the required weight using metal pieces of various masses.

\section{Data Acquisition}

EMG data were acquired using an eight channel wireless EMG systems (Delsys Inc., Boston, MA, USA). Parallel bar active surface electrodes (DE-2.3 EMG

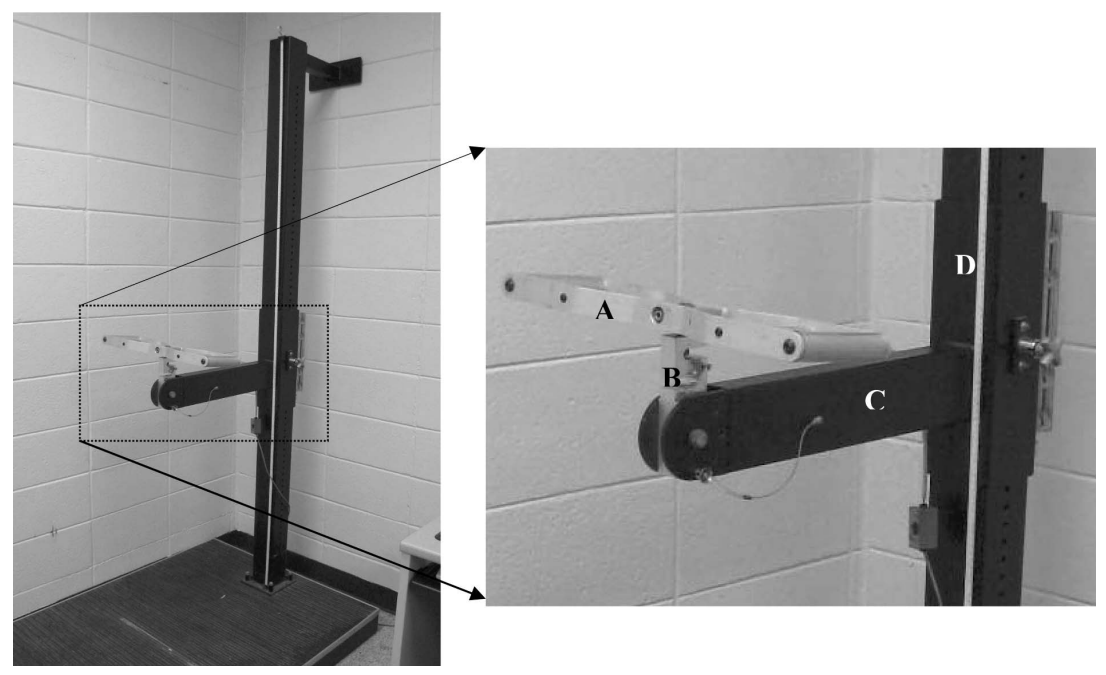

Fig. 2. Isometric strength testing equipment, (A) handle, (B) load cell, (C) horizontal lever arm, (D) vertical post. 

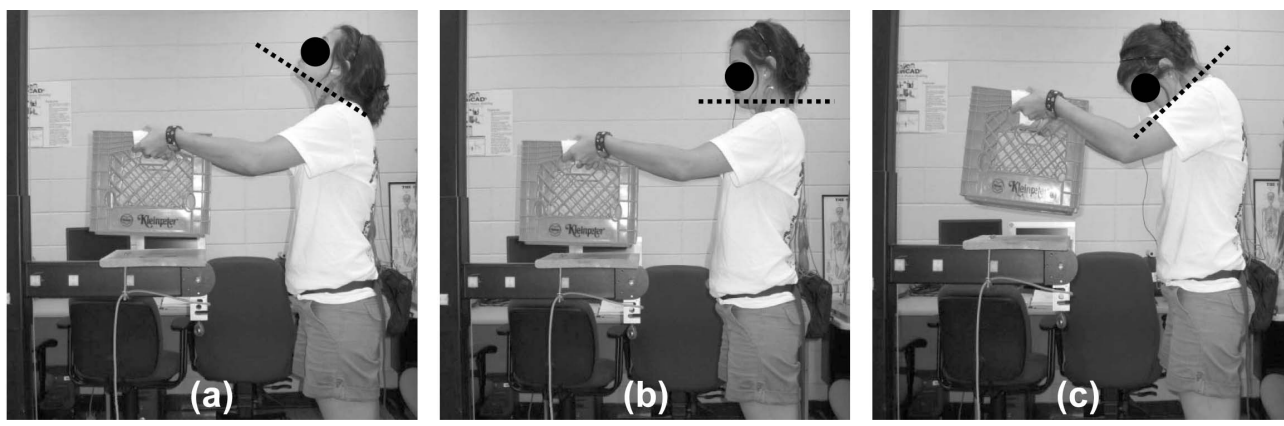

Fig. 3. A participant performing static lifting task at the shoulder height with her neck at (a) maximally extended, (b) neutral, and (c) maximally flexed positions.

Sensors, Delsys Inc., Boston, MA, USA) were used for EMG signal acquisition. The sensor contacts are made of $99.9 \%$ pure silver bars measuring $10 \mathrm{~mm}$ in length, $1 \mathrm{~mm}$ in diameter, and spaced $10 \mathrm{~mm}$ apart. Prior to the placement of the EMG electrodes the skin underneath the anatomical landmarks was shaved (if required) and cleaned with $70 \%$ alcohol.

EMG from the sternocleidomastoid muscle was recorded by placing an electrode along a line drawn from the sternal notch to the mastoid process, at $1 / 3$ the length of the line from the mastoid process. Electrodes were located midway between the innervation zone (the middle of the muscle ${ }^{14)}$ ) and the insertion of the muscle at the mastoid process.

EMG from the upper trapezius muscle was recorded using two electrode locations (lower and upper). The lower electrode was placed at a location along the line joining the acromion and $\mathrm{C} 7$, at $1 / 3$ the distance from the acromion, according to published recommendations ${ }^{15}$. An additional upper electrode was placed between the occiput and $\mathrm{C} 7$, at the level of $\mathrm{C} 4$ to precisely examine the activities of the upper trapezius muscle in the cervical region ${ }^{16)}$. To our knowledge no standardized electrode location for the upper trapezius muscle along the $\mathrm{C} 4$ level have been mentioned previously in the literature; therefore, electrode location along the $\mathrm{C} 4$ level was finalized based on the measurements from the skeletal models of cervical spine and pilot EMG data collection. The level of $\mathrm{C} 4$ was determined by marking a horizontal line at 2.5 times the distance between the $\mathrm{C} 6-\mathrm{C} 7$ vertebrae above the $\mathrm{C} 7$. The electrode at this location was placed slightly inclined (approximately 35 degrees) to the vertical line between spinous processes of the $\mathrm{C} 7$ and $\mathrm{C} 4$.

EMG data from the neck muscles were recorded from both left and right sides using a total of six electrode locations. A disposable reference electrode was applied to the forehead. EMG data was collected continuously during the experimental trials at the rate of $1,000 \mathrm{~Hz}$.

\section{Data analysis}

EMG data during all the exertions were analyzed for the last five seconds of each exertion. The raw EMG signal from each electrode location was demeaned and then full-wave rectified. To demean the signal, the mean of the raw EMG data was subtracted from each EMG data point. The full wave rectified EMG signal was then low pass filtered at $4 \mathrm{~Hz}$ using a fourth-order dual pass Butterworth digital filter, to form a linear envelope ${ }^{17)}$ and mean absolute values (MAV) were obtained ${ }^{18}$. The resulting data were averaged i.e. the low pass filtered EMG data from each electrode locations during a static lifting trial were averaged to determine the averaged $M A V$ i.e. $A-M A V$. For any static lifting trial, six $M A V$ were obtained for a participant corresponding to six electrode locations.

Comparison of EMG between and within participants involves normalizing the EMG data. Typically EMG can be normalized with respect to (1) muscle activation at the maximum voluntary contraction or percentage of maximum voluntary contraction ${ }^{19,20)}$, (2) reference muscle activation while performing standardized task ${ }^{21,22)}$, (3) the peak or mean activation during the tasks ${ }^{23-25)}$. Although normalization with respect to maximum voluntary contraction has been extensively used in the literature, the ability to maximally activate all motor units depends on many factors, such as the muscle activated, training level, motivation, and most importantly posture $^{26)}$. In the cervical spine, considering the wide range of motion, neck muscles' moment arm and the length-tension relationship alter greatly depending on the neck posture. The neck posture governs the activation as well as ability to exert maximum force for the neck muscles. The anterior neck muscles can be most active at certain neck postures, at which posterior muscles are minimally activated $^{27)}$. One of the main objectives of this research was to evaluate the effect of the neck posture, and since major anterior as well as posterior muscles were evaluated, EMG data were normalized using the maximum (peak) 
activation during tasks.

The average MAV was determined for each electrode location during all the experimental trials. The MAV data were normalized with respect to the maximum average MAV. For both muscles the maximum average MAV was observed at $75 \%$ weight condition. The MAV for the upper trapezius muscle was observed at flexed neck posture (both locations), and for the sternocleidomastoid muscle it was observed at extended neck posture. The EMG MAV from all the electrodes was normalized to determine the Normalized MAV (N-MAV):

$$
N-M A V_{m, n, o, p}=\frac{A-M A V(m, n, o, p)}{\operatorname{Max}\left[\left(\operatorname{MAV}\left(m, n_{=75 \%}, o, p\right)\right)\right]}
$$

Where,

$m=$ neck posture; maximally extended, neutral, maximally flexed

$n=$ weight condition; $25 \%, 50 \%, 75 \%$ of maximum shoulder height static strength

$o=$ electrode location; right, left on sternocleidomastoid and right, left, upper, lower on upper trapezius muscles

$p=$ participant; 1 to 15

Statistical analysis was performed using a two-factor (lifting weight $\times$ neck posture) repeated measures analysis of variance (ANOVA) model. The lifting weight $(25 \%, 50 \%$, and $75 \%)$ and neck posture (maximally extended, neutral, and maximally flexed) were treated as the within subject variables. The N-MAV of sternocleidomastoid and upper trapezius muscles (both upper and lower locations) were the dependent variables. Post hoc trend analysis was performed using Tukey's HSD
(Honestly Significant Differences) test when necessary. The significance level was set at $95 \%$.

\section{Results}

No difference was found in the EMG data collected from the right and left side ( $p$ values for sternocleidomastoid, upper trapezius muscle along the $\mathrm{C} 4$ level, and upper trapezius muscle along the $\mathrm{C} 7$ level were $0.26,0.26$, 0.32 , respectively) and therefore data from right and left side was averaged for further statistical analysis.

\section{Effect of weight}

Increase in the weight from $25 \%$ to $50 \%$ to $75 \%$ had significant effects on the activities of the sternocleidomastoid muscle $(p<0.0001)$ (Fig. 4). At neutral neck posture, based on the post hoc trend analysis, the EMG activation at $75 \%$ weight condition was significantly higher than the respective $25 \%$ and $50 \%$ weight conditions (at $\alpha=0.05$ ) (Table 1). At extended and flexed neck postures, increase in the EMG activation with respect to the increase in weight from $25 \%$ to $75 \%$ and from $50 \%$ to $75 \%$ was statistically significant. At either neck posture, EMG activation increased with the increase in the weight from $25 \%$ to $50 \%$, but the increase was statistically not significant.

The activities of the upper trapezius muscle along the $\mathrm{C} 4$ level increased significantly with the increase in the weight from $25 \%$ to $50 \%$ to $75 \%(p<0.0001)$ (Fig. 5(a)). Based on the post hoc trend analysis, at all three neck postures, the EMG activation at 50\% weight condition was significantly higher than the respective $25 \%$ weight condition; and at $75 \%$ weight condition was significantly higher than the respective $25 \%$ and $50 \%$ weight condi-

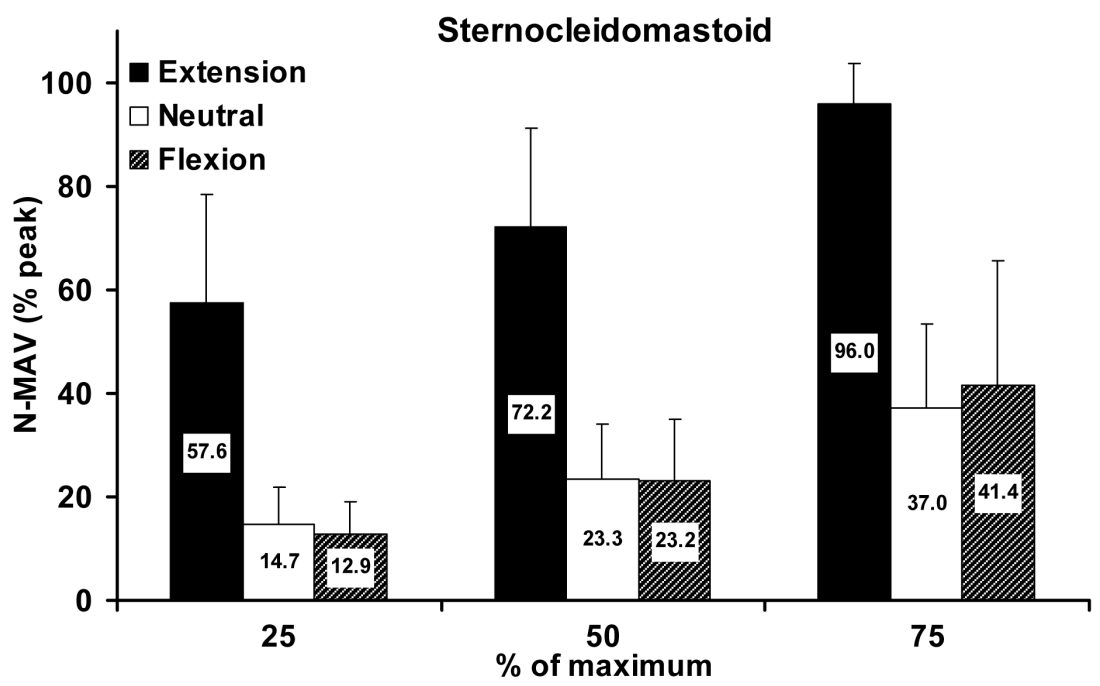

Fig. 4. Behavior of the sternocleidomastoid muscle (N-EMG values) at $25 \%, 50 \%$, and $75 \%$ weight conditions at neutral, flexed and extended neck postures. 
Table 1. N-MAV (\%) values for the sternocleidomastoid and upper trapezius muscle (mean $\pm \mathrm{SD})$

\begin{tabular}{|c|c|c|c|}
\hline \multirow[b]{3}{*}{ Weight } & \multicolumn{3}{|c|}{ Sternocleidomastoid } \\
\hline & \multicolumn{3}{|c|}{ Neck posture } \\
\hline & Extension & Neutral & Flexion \\
\hline $25 \%$ & $57.6( \pm 20.9)^{* a, x}$ & $14.7( \pm 7.3)^{\mathrm{b}, \mathrm{x}}$ & $12.9( \pm 6.1)^{\mathrm{b}, \mathrm{x}}$ \\
\hline $50 \%$ & $72.2( \pm 19.2)^{\mathrm{a}, \mathrm{y}}$ & $23.3( \pm 10.7)^{b, x}$ & $23.2( \pm 11.8)^{\mathrm{b}, \mathrm{x}}$ \\
\hline \multirow[t]{2}{*}{$75 \%$} & $96.0( \pm 7.8)^{\mathrm{a}, \mathrm{z}}$ & $37.0( \pm 16.5)^{\mathrm{b}, \mathrm{y}}$ & $41.4( \pm 24.3)^{\mathrm{b}, \mathrm{y}}$ \\
\hline & \multicolumn{3}{|c|}{ Upper trapezius (along the $\mathrm{C} 4$ level) } \\
\hline $25 \%$ & $34.1( \pm 13.6)^{\mathrm{a}, \mathrm{x}}$ & $33.6( \pm 9.8)^{\mathrm{a}, \mathrm{x}}$ & $40.8( \pm 15.3)^{\mathrm{a}, \mathrm{x}}$ \\
\hline $50 \%$ & $51.0( \pm 19.1)^{\mathrm{a}, \mathrm{y}}$ & $53.4( \pm 13.7)^{\mathrm{a}, \mathrm{y}}$ & $66.4( \pm 18.5)^{\mathrm{b}, \mathrm{y}}$ \\
\hline \multirow[t]{2}{*}{$75 \%$} & $62.8( \pm 13.4)^{\mathrm{a}, \mathrm{z}}$ & $70.6( \pm 19.9)^{\mathrm{a}, \mathrm{z}}$ & $95.9( \pm 10.2)^{\mathrm{b}, \mathrm{z}}$ \\
\hline & \multicolumn{3}{|c|}{ Upper trapezius (along the $\mathrm{C} 7$ level) } \\
\hline $25 \%$ & $36.6( \pm 14.7)^{\mathrm{a}, \mathrm{x}}$ & $37.7( \pm 9.1)^{\mathrm{a}, \mathrm{x}}$ & $42.1( \pm 17.1)^{\mathrm{a}, \mathrm{x}}$ \\
\hline $50 \%$ & $53.3( \pm 17.2)^{\mathrm{a}, \mathrm{y}}$ & $59.1( \pm 11.6)^{\mathrm{a}, \mathrm{y}}$ & $67.5( \pm 18.7)^{\mathrm{b}, \mathrm{y}}$ \\
\hline $75 \%$ & $73.0( \pm 16.2)^{\mathrm{a}, \mathrm{z}}$ & $75.2( \pm 17.0)^{\mathrm{a}, \mathrm{z}}$ & $95.3( \pm 10.6)^{\mathrm{b}, \mathrm{z}}$ \\
\hline
\end{tabular}

*The values marked with the different letters are statistically significant. Letters $\mathrm{a}, \mathrm{b}$, and $\mathrm{c}$ are used for neck postures and $\mathrm{x}, \mathrm{y}$, and $\mathrm{z}$ are used for weight conditions, e.g. for sternocleidomastoid muscle at $25 \%$ weight condition N-MAV during extended neck posture was higher than the corresponding neutral and flexed postures, and lower than the corresponding $50 \%$ and $75 \%$ weight conditions.

tions (at $\alpha=0.05$ ) (Table 1).

For the upper trapezius muscle along the $\mathrm{C} 7$ level, increase in the weight significantly increased the EMG activation level $(p<0.0001)$ (Fig. 5(b)). Similar to the upper trapezius muscle along the $\mathrm{C} 4$ level, increase in the weight from $25 \%$ to $50 \%, 25 \%$ to $75 \%$, and $50 \%$ to $75 \%$ significantly increased the activities along the $\mathrm{C} 7$ level (at $\alpha=0.05$ ) (Table 1).

\section{Effect of the Neck Posture}

The activation of the sternocleidomastoid muscle was significantly affected by the neck posture $(p<0.0001)$ (Fig. 4). At each weight condition, the activation of the sternocleidomastoid muscle was significantly higher at the extended neck posture than the respective neutral and flexed neck postures (Table 1). The activation of the sternocleidomastoid muscle at the neutral and flexed neck postures was found statistically identical at all weight conditions.

Neck posture significantly affected the activation of upper trapezius muscle along the $\mathrm{C} 4$ level $(p<0.0001)$ (Fig. 5(a)). At 25\% weight condition the muscle was found most active at the flexed neck posture; however, the values were statistically not significant (Table 1). At $50 \%$ and $75 \%$ weight conditions, the muscle was found most active at the flexed neck posture followed by the neutral and extended neck posture. The increase in the activation level with the change in the neck posture from neutral to flexed and from extended to flexed was statistically significant. The increase in the activation level with the change in the neck posture from extended to neutral was statistically not significant.

The activation of upper trapezius muscle along C7 level was also significantly affected by the neck posture $(p=0.0003)$ (Fig. 5(b)). At each weight condition, the muscle was most active at the flexed neck posture followed by the neutral and the extended neck posture (Table 1). In terms of statistical significance, at 50\% weight condition, the activation at the flexed neck posture was significantly higher than the corresponding extended neck posture. At $75 \%$ weight condition, the activation at the flexed neck posture was significantly higher than the corresponding extended and neutral neck postures.

\section{Discussion}

The main aim of this study was to understand the physical risk factors associated with neck disorders among construction workers. A manual material-handling task common at various construction sites i.e. lifting and/or holding of heavy objects at the shoulder height was stud-
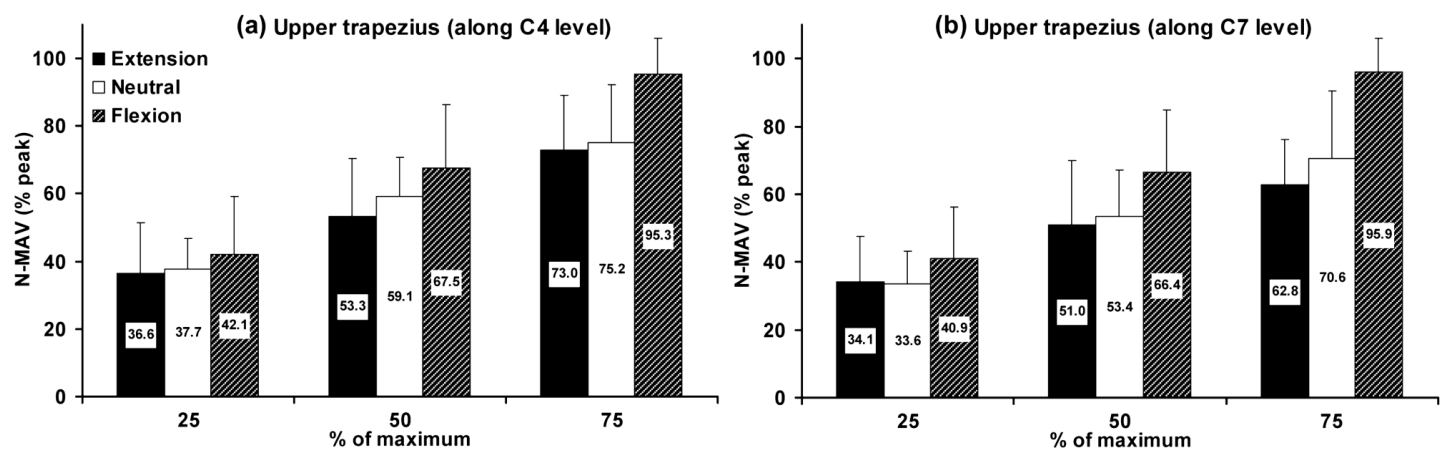

Fig. 5. Behavior of the upper trapezius muscle along (a) $\mathrm{C} 4$ level and (b) $\mathrm{C} 7$ level (N-EMG values) at $25 \%, 50 \%$, and $75 \%$ weight conditions at neutral, flexed and extended neck postures. 
ied. The contribution of neck muscles was evaluated biomechanically by studying the EMG activities of major anterior and posterior neck muscles at neutral, maximally flexed, and maximally extended neck postures.

The weight lifted substantially affected the contribution of the neck muscles. In the case of the anterior neck muscle (sternocleidomastoid muscle), increased muscle activation with increased weight was significant at extended neck posture and mostly for higher weights $(50 \%$, and $75 \%)$ at neutral and flexed neck postures. For the posterior neck muscles (upper trapezius muscle) along $\mathrm{C} 4$ as well as $\mathrm{C} 7$ levels, at all the neck postures, a significant weight-muscle activation relationship was observed. This observed increase in the activation of the upper trapezius muscle along the $\mathrm{C} 7$ level with the increase in the weight at the shoulder height is consistent with previous investigations $^{7,15,28,29)}$.

Posture had a significant impact on the activation level of the neck muscles. Independent of the weight lifted the sternocleidomastoid muscle was most active at the extended neck posture. The muscle activation at the neutral and flexed neck postures was identical. The upper trapezius muscle was most active at the flexed neck posture followed by the neutral and extended neck postures. However, this neck posture dependent behavior of the upper trapezius muscle was found to be significant only at the higher weight conditions, i.e. while lifting $50 \%$ and $75 \%$ weights, flexed neck caused substantially higher muscle activation compared to the neutral and extended neck postures. Consistent with our findings, previously, increased activation of the upper trapezius muscle along the $\mathrm{C} 7$ level, at the flexed neck posture was reported in a number of studies evaluating sitting work postures ${ }^{30-32}$. Moreover the observed neck-posture and muscle-activation trend is in agreement with the muscle force-length relationship i.e. lower activation at shorter length and higher values at increased length ${ }^{33)}$.

The upper trapezius muscle, especially along the $\mathrm{C} 7$ level, has been widely studied in occupational investigations to evaluate neck and upper extremity disorders. To our knowledge no previous study evaluating occupational tasks or forceful arm exertions has reported the activities of the sternocleidomastoid muscle and the upper trapezius muscle in the cervical region. While evaluating neck disorders, understanding the activation of these muscles is vital, as they are bigger (surface) muscles in the neck region and anatomically couple the shoulder to the skull. Such an anatomical orientation may require these muscles to support the shoulder during forceful arm exertions. In confirmation with our claim, the results of this study clearly show that, similar to the upper trapezius muscle along the $\mathrm{C} 7$, the activation of the sternocleidomastoid muscle and the upper trapezius muscle in the cervical region was sensitive to the lifting weight as well as neck posture.

Overall, the results of this study indicate that the neck muscles play an active role during lifting and holding tasks at shoulder heights. While translating EMG activation of the neck muscles into physical risk factors associated with neck disorders, it is important to understand the possible MSD pathways. Armstrong et al. ${ }^{34)}$ presented a conceptual model describing the pathways involved in the pathogenesis of cumulative neck and upper limb MSD. During work activities, the internal forces acting upon the musculoskeletal system require a response by the body. The response could be physiological or biomechanical in nature e.g. increased circulation, local muscle fatigue etc. The cumulative work activities could require continued or excessive response, which might affect the body's ability to deal with further responses. With the repetition and/or accumulation of this phenomenon over the time, the reorganization or the regeneration process of the body tissue might be affected, causing structural tissue deformation.

Routine construction work requires lifting objects to shoulder height repetitively. The sustained activity in neck muscles during these tasks can be linked to (1) reduced blood flow, (2) repetitive loading of tendons, (3) rupture of the muscle's z-discs, and (4) contractile forces acting on the cervical spine ${ }^{35}$. The repetitive loading of the muscles and tendons has been associated with muscle specific neck disorders such as tension neck syndrome, while that of cervical vertebrae has been associated with degenerative disorders such as disc herniation and cervical spondylosis ${ }^{34)}$. Thus active contribution of the neck muscles during the lifting and holding of heavy objects at shoulder height could be probable risk factors associated with prevalent neck disorders among construction workers. Considering the inherent association of lifting tasks with the construction profession, alternative material (e.g. light-weight concrete blocks ${ }^{7}$, pre-blended mortar and grout mix ${ }^{1)}$ ), methods, and tools (Vacuum lifters ${ }^{1)}$ ) could be used to minimize the potential of neck injuries among construction workers. Future studies could be performed to find alternative construction work strategies and also to validate existing interventions.

The laboratory based nature of this study imposes a few limitations. First, the actual construction sites are characterized by harsh outdoor environments due to noise, vibration, space, and time constraints. Such task specific factors could impose psychosocial stress further impacting muscle activation. Second, for standardization purposes, the participants lifted certain percentages of their maximum strength. In actual work conditions workers lift weights of different sizes and dimensions regardless of body size or strength. Third, relatively younger peo- 
ple with less experience in physically demanding work were tested. Considering the relatively awkward lifting posture tested in this study, the ability of the participants to lift at shoulder height might have been less than actual construction workers. Moreover, it is possible that the muscle activation patterns in experienced workers may be different than the relatively inexperienced university students. Future studies performed at construction sites, evaluating actual construction tasks and workers could provide us a more comprehensive understanding of the neck disorders among construction workers.

In summary, this study concludes that lifting and holding weights at shoulder height result in increased activity in the superficial neck flexors and upper trapezius which may be a source of neck MSD prevalent among construction workers.

\section{References}

1) National Institute for Occupational Safety and Health. Simple Solutions: Ergonomics for Construction Workers 2007. NIOSH Publication No. 2007-122. http://www. cdc.gov/niosh/docs/2007-122/. Accessed May 13, 2009.

2) Schneider SP (2001) Musculoskeletal injuries in construction: a review of the literature. Appl Occup Environ Hyg 16, 1056-64.

3) Rempel D, Star D, Gibbons B, Barr A, Janowitz I (2007) Development and evaluation of a new device for overhead drilling. Prof Safety 52, 30-5.

4) Silverstein B, Viikari-Juntura E, Kalat J (2002) Use of a prevention index to identify industries at high risk for work-related musculoskeletal disorders of the neck, back, and upper extremity in Washington state, 1990-1998. Am J Ind Med 41, 149-69.

5) Holmstrom E, Moritz U, Engholm G (1995) Musculoskeletal disorders in construction workers. Occup Med 10, 295-312.

6) Guo HR, Chang YC, Yeh WY, Chen CW, Guo YL (2004) Prevalence of musculoskeletal disorder among workers in Taiwan: a nationwide study. J Occup Health 46, 26-36.

7) Anton D, Rosecrance JC, Gerr F, Merlino LA, Cook TM (2005) Effect of concrete block weight and wall height on electromyographic activity and heart rate of masons. Ergonomics 48, 1314-30.

8) Kim S, Seol H, Ikuma LH, Nussbaum MA (2008) Knowledge and opinions of designers of industrialized wall panels regarding incorporating ergonomics in design. Int J Ind Ergon 38, 150-7.

9) Walker-Bone K, Cooper C (2005) Hard work never hurt anyone: or did it? A review of occupational associations with soft tissue musculoskeletal disorders of the neck and upper limb. Ann Rheum Dis 64, 1391-6.

10) Malchaire J, Cock N, Vergracht S (2001) Review of the factors associated with musculoskeletal problems in epidemiological studies. Int Arch Occup Environ Health
74, 79-90.

11) Ariens GA, van Mechelen W, Bongers PM, Bouter LM, van der Wal G (2000) Physical risk factors for neck pain. Scand J Work Environ Health 26, 7-19.

12) Hagberg M, Wegman DH (1987) Prevalence rates and odds ratios of shoulder-neck diseases in different occupational groups. Brit J Ind Med 44, 602-10.

13) Viikari-Juntura E, Riihimaki $H$, Tola $S$, Videman $T$, Mutanen P (1994) Neck trouble in machine operating, dynamic physical work and sedentary work: a prospective study on occupational and individual risk factors. $\mathrm{J}$ Clin Epidemiol 47, 1411-22.

14) Falla D, Dall'Alba P, Rainoldi A, Merletti R, Jull G (2002) Repeatability of surface EMG variables in the sternocleidomastoid and anterior scalene muscles. Eur J Appl Physiol 87, 542-9.

15) Farina D, Madeleine $P$, Graven-Nielsen $T$, Merletti $R$, Arendt-Nielsen L (2002) Standardising surface electromyogram recordings for assessment of activity and fatigue in the human upper trapezius muscle. Eur J Appl Physiol 86, 469-78.

16) Johnson GR, Pandyan AD (2005) The activity in the three regions of the trapezius under controlled loading conditions - an experimental and modelling study. Clin Biomech 20, 155-61.

17) Burnett A, Green J, Netto K, Rodrigues J (2007) Examination of EMG normalisation methods for the study of the posterior and posterolateral neck muscles in healthy controls. J Electromyogr Kines 17, 635-41.

18) Acierno SP, Baratta RV, Solomonow M (1995) A practical guide to electromyography for biomechanics. Unpublished report, Louisiana State University, New Orleans.

19) Finsen L (1999) Biomechanical aspects of occupational neck postures during dental work. Int J Ind Ergon 23, 397-406.

20) Sommerich CM, Joines S, Psihogios JP (2001) Effects of computer monitor viewing angle and related factors on strain, performance, and preference outcomes. Hum Factors 43, 39-55.

21) Mathiassen SE, Winkel J (1990) Electromyographic activity in the shoulder-neck region according to arm position and glenohumeral torque. Eur J Appl Physiol 61, 370-9.

22) Turville KL, Psihogios JP, Ulmer TR, Mirka GA (1998) The effects of video display terminal height on the operator: a comparison of the 15 degree and 40 degree recommendations. Appl Ergon 29, 239-46.

23) Yang JF, Winter DA (1984) Electromyographic amplitude normalization methods: improving their sensitivity as diagnostic tools in gait analysis. Arch Phys Med Rehab 65, 517-21.

24) Vander Linden DW, Wilhelm IJ (1991) Electromyographic and cinematographic analysis of movement from a kneeling to a standing position in healthy 5-to 7-yearold children. Phys Ther 71, 14-26.

25) Winter DA, Yack HJ (1987) EMG profiles during nor- 
mal human walking: stride-to-stride and inter-subject variability. Electroen Clin Neuro 67, 402-11.

26) Soderberg GL, Knutson LM (2000) A guide for use and interpretation of kinesiologic electromyographic data. Phys Ther 80, 485-98.

27) Sommerich CM, Joines SM, Hermans V, Moon SD (2000) Use of surface electromyography to estimate neck muscle activity. J Electromyogr Kines 10, 377-98.

28) Åström C, Lindkvist M, Burström L, Sundelin G, Karlsson JS (2007) Changes in EMG activity in the upper trapezius muscle due to local vibration exposure. J Electromyogr Kines 19, 407-15.

29) Öberg T, Sandsjö L, Kadefors R (1994) Subjective and objective evaluation of shoulder muscle fatigue. Ergonomics 37, 1323-33.

30) Schüldt K, Ekholm J, Harms-Ringdahl K, Németh G, Arborelius UP (1986) Effects of changes in sitting work posture on static neck and shoulder muscle activity. Ergonomics 29, 1525-37.

31) Harms-Ringdahl K, Ekholm J, Schüldt K, Németh G,
Arborelius UP (1986) Load moments and myoelectric activity when the cervical spine is held in full flexion and extension. Ergonomics 29, 1539-52.

32) Villanueva MBG, Jonai $H$, Sotoyama M, Hisanaga N, Takeuchi Y, Saito S (1997) Sitting posture and neck and shoulder muscle activities at different screen height settings of the visual display terminal. Ind Health 35, $330-6$.

33) Chaffin DB, Andersson G, Martin BJ (1991) Occupational biomechanics. Wiley Publisher, New York.

34) Armstrong TJ, Buckle P, Fine LJ, Hagberg M, Jonsson B, Kilbom A, Kuorinka I, Silverstein BA, Sjogaard G, Viikari-Juntura ERA (1993) A conceptual model for work-related neck and upper-limb musculoskeletal disorders. Scand J Work Environ Health 19, 73-84.

35) Kroemer KHE (1989) Cumulative trauma disorders. Appl Ergon 20, 274-80.

36) Barbe M, Barr A (2006) Inflammation and the pathophysiology of work-related musculoskeletal disorders. Brain Behav Immun 20, 423-9. 